1 Scalable ${ }^{18} \mathrm{~F}$ Processing Conditions for Copper-Mediated

2 Radiofluorination Chemistry Facilitate "Design of Experiments" (DoE)

3 Optimization Studies and Afford an Improved Synthesis of [ $\left.{ }^{18} \mathrm{~F}\right]$ Olaparib.

4 Gregory D. Bowden ${ }^{1}$, Nantanat Chailanggar, ${ }^{1}$ Bernd J. Pichler ${ }^{1,2,3}$, Andreas Maurer ${ }^{1,2}$

$5 \quad{ }^{1}$ Werner Siemens Imaging Center, Department of Preclinical Imaging and Radiopharmacy, Eberhard Karls University,

6 Tübingen, Germany

$7 \quad{ }^{2}$ Cluster of Excellence iFIT (EXC 2180) "Image-Guided and Functionally Instructed Tumor Therapies", Eberhard Karls

8 University, Tuebingen, Germany

${ }^{3}$ German Cancer Research Center, German Cancer Consortium DKTK, Partner Site Tubingen, D-72076 Tubingen, Germany

Abstract

A convenient, scalable, and azeotropic drying free method for processing $\left[{ }^{18} \mathrm{~F}\right]$ fluoride as base free $\left[{ }^{18} \mathrm{~F}\right] \mathrm{TBAF}$ is reported and applied to copper-mediated radiofluorination (CMRF) radiosyntheses. A central feature of this method is that a single production of $\left[{ }^{18} \mathrm{~F}\right] \mathrm{TBAF}$ can be divided into small aliquots that can be used to perform multiple small-scale reactions in DoE optimization studies. The results of these studies can then be reliably translated to full batch tracer productions using automated synthesizers. This processing technique was successfully applied to the manual DoE optimization, DoE study validation, and subsequent full-batch automation of the PARP-1 tracer $\left[{ }^{18} \mathrm{~F}\right]$ olaparib. After DoE optimization, we were able to produce $\left[{ }^{18} \mathrm{~F}\right]$ olaparib in high radiochemical yields via both manual (\%RCY (CMRF step only) $\left.=78 \pm 6 \%, \mathrm{n}=4\right)$ and automated (up to $80 \%$ radiochemical yield (\%RCY); $41 \%$ activity yield (\%AY)) radiosynthesis procedures. This work further demonstrates the power of the DoE approach for improving the radiochemical yields and radiosynthesis performance of clinically relevant tracer productions.

\title{
1. Article
}

As the use of positron emission tomography (PET) as a molecular imaging tool continues to grow, so will the demand for novel clinically relevant PET tracers. The development of new automatable radiochemical methodologies, particularly for ${ }^{18} \mathrm{~F}$ radiochemistry, has become an important area of research to meet this demand. The copper-mediated radiofluorination (CMRF) family of aromatic radiofluorinations is a recent example of a "next-generation" radiochemical methodology that has become a highly relevant tool for radiolabeling aromatic compounds with ${ }^{18} \mathrm{~F}^{1-3}$ The methodology's broad scope and operationally simplicity have meant that radiopharmacy research groups have readily adopted it as a convenient method for rapidly developing novel tracers for preclinical evaluation. ${ }^{4}$ As these tracers become more utilized by preclinical and clinical imaging scientists, radiopharmacists must adapt "next-gen" radiolabeling methods, 
like CMRF chemistry, to meet the expanding tracer production demands. ${ }^{5}$ Radiosynthesis optimization is an essential part of this process. A well-optimized radiosynthesis (in terms of both chemistry and purification) is more reliable and ensures maximal activity yields, thus making radiopharmaceutical production more efficient in the light of the continuously increasing demand for PET radiotracers. Additionally, carefully optimizing radiosyntheses can help minimize the use of potentially toxic reagents, precursors, solvents, or catalysts. From a GMP perspective, simplified tracer production, purification, and expedited quality control procedures can make it easier for radiopharmacies to meet the regulatory requirements regarding solvent and impurity content.

"Design of Experiments" (DoE) is a statistical toolset that aims to provide a detailed model of processes' performance with respect to multiple experimental variables (factors) while minimizing the number of optimization experiments. ${ }^{6}$ We have previously reported that using a DoE approach expedites the radiosynthesis optimization process in terms of cost and time and can extract practically useful information in the form of response surface models (RSMs). ${ }^{7}$ This information can then be used to develop more efficient radiosynthesis protocols with more limited use of harmful substances. This work laid the basis for a DoE based tracer development pipeline that increases the rate at which radiopharmacists can establish, optimize, automate, and deliver CMRF-based tracer productions for preclinical study.

This initial work focused on optimizing reaction conditions and assumed little influence from the ${ }^{18} \mathrm{~F}$ processing method. However, the processing of $\left[{ }^{18} \mathrm{~F}\right]$ fluoride is an essential step in any ${ }^{18} \mathrm{~F}$-radiosynthesis, and it can indeed have a significant influence on the final yield. The purpose of ${ }^{18} \mathrm{~F}$ processing is to dehydrate the $\left[{ }^{18} \mathrm{~F}\right]$ fluoride ion and provide an appropriate counter ion to maximize the nucleophilicity of the $\left[{ }^{18} \mathrm{~F}\right]$ fluoride ion before its reaction with a substrate. For practical reasons, the DoE studies mentioned above were performed using small aliquots $(80 \mu \mathrm{l})$ of a $\left[{ }^{18} \mathrm{~F}\right] \mathrm{KF}$ solution eluted from a single QMA (quaternary methylammonium resin) cartridge with a solution of potassium triflate and potassium carbonate in water (Figure 1: Method A), as initially described by Makaravage et al. ${ }^{3}$ These aliquots of $\left[{ }^{18} \mathrm{~F}\right] \mathrm{KF}$ solution were then transferred into 5-6 reaction vessels and were individually azeotropically dried with three additions of acetonitrile $(1.5 \mathrm{ml})$ by the standard method. While laborious and time-consuming, this method ensured a relatively even distribution of $\left[{ }^{18} \mathrm{~F}\right]$ fluoride and QMA eluent salts between the reaction vessels, reducing experimental variability in the DoE studies. It also allowed multiple experiments to be conducted from one delivery of cyclotron produced $\left[{ }^{18} \mathrm{~F}\right]$ fluoride, making the use of multi-experiment DoE studies a practical possibility. However, in many instances, the results obtained from these DoE studies did not scale up when performed with "batch" quantities of QMA eluents. The deleterious effects of larger amounts of carbonate bases and phase transfer catalysts (PTCs) present in QMA eluent solutions on CMRF reaction performance have been well documented. ${ }^{8-10}$ 
To further our work in establishing a rapid tracer development and radiosynthesis optimization pipeline around the DoE approach, we required an ${ }^{18} \mathrm{~F}$ processing method that met the following requirements: 1 ) The procedure needed to be operationally simple, fast, scalable, and automatable using standard radiosynthesis modules. 2) Given our desire to carefully study the effect of various reaction components (e.g., pyridine load, not discussed in this work) on CMRF reactions' performance, the QMA eluent should minimize any components that may affect or interact with either the copper-mediator or the precursor. We thus wanted to avoid the use of eluents that included the precursor, catalyst, or pyridinium salts (as successfully employed by Zhang et al. and Antuganov et al. $)^{11,12} 3$ ) The method should eliminate the use of strongly basic anions (e.g., carbonates) and cryptand PTCs from the QMA preconditioning and eluent solutions to ensure true scalability from "aliquoted" DoE reaction studies to full "batch" radiosyntheses.

Several groups have investigated alternative QMA cartridge eluents that are less basic and better suited to CMRF chemistry than the classic combination of potassium carbonate and kryptofix ${ }^{\circledR} 2.2 .2\left(\mathrm{~K}_{222}\right) .{ }^{10-17}$ One of the more widely adopted methods has been the alcohol-enhanced CMRF developed by Zischler et al. (Figure 1: Method B), whereby the $\left[{ }^{18} \mathrm{~F}\right]$ fluoride was efficiently eluted from the QMA using tetraethylammonium bicarbonate (TEAB) in an alcoholic solvent. ${ }^{16}$ This method could provide processed ${ }^{18} \mathrm{~F}$ from the QMA cartridge with high elution efficiency and could be used to synthesize several radiotracers in good to excellent radiochemical yields. However, the technique suffered a significant drawback: the aqueous ${ }^{18} \mathrm{~F}$ needed to be loaded onto the cartridge in the reverse direction to ensure maximal elution efficiency. This "back-flushing" procedure adds operational complexity and increases the probability of introducing radiochemical impurities from the irradiated cyclotron target water into the reactor vessel.

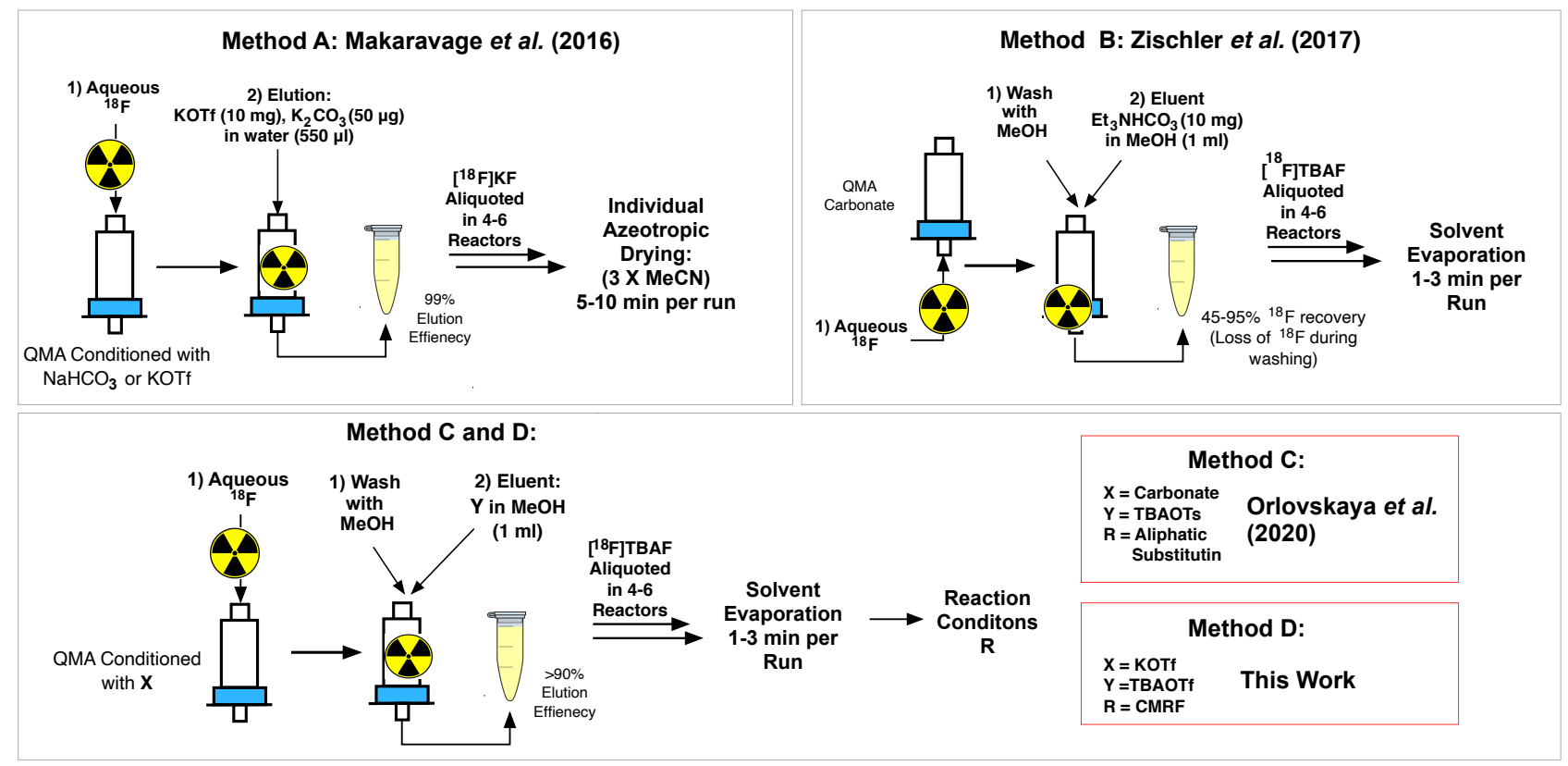

Figure 1: Previous (methods A-C) and current (method D) work into the development of CMRF specific ${ }^{18} \mathrm{~F}$ processing methods. 

Orlovskaya et al. showed that tetrabutylammonium tosylate (TBAOTs) in an alcoholic solvent was able to efficiently elute $\left[{ }^{18} \mathrm{~F}\right]$ fluoride from a QMA-carbonate cartridge $\left(\mathrm{QMA}-\mathrm{HCO}_{3}, \mathrm{QMA}\right.$ cartridge with carbonate counter ion) (Figure 1: Method C). ${ }^{18}$ TBAOTs was also found to be suitable as a stable and inert PTC for traditional $S_{N} 2$ radiofluorinations. The authors were able to show that TBAOTs in ethanol could elute ${ }^{18} \mathrm{~F}$ from a $\mathrm{QMA}-\mathrm{HCO}_{3}$ cartridge with a high elution efficiency (>90\%) without needing to load the ${ }^{18} \mathrm{~F}$ onto the QMA cartridge in the reverse direction. The authors later reported the CMRF compatibility of similar ${ }^{18} \mathrm{~F}$ processing chemistry (using the "back-flushing" protocol discussed above) when applied to the CMRF synthesis of 6-L-[ $\left.{ }^{18} \mathrm{~F}\right]$ FDOPA. ${ }^{19}$ Inspired by this fast and operationally simple approach, we aimed to develop an ${ }^{18} \mathrm{~F}$ processing method that entirely eliminates the presence of carbonate base from a CMRF reaction mixture by preconditioning the QMA cartridge with an organic sulfonic acid (Figure 1: Method D).

A series of experiments were performed to evaluate and compare different ${ }^{18} \mathrm{~F}$ processing protocols, each featuring an ${ }^{18} \mathrm{~F}$ processing step, followed by either azeotropic drying or solvent evaporation under a stream of argon (Table 1). Each run was performed using a batch ${ }^{18} \mathrm{~F}$ elution from a single QMA cartridge. An unoptimized model CMRF reaction using 4-biphenylboronic acid pinacol ester (15 $\mu$ mol), copper (II) triflate $(5 \mu \mathrm{mol})$, and pyridine $(25 \mu \mathrm{mol})$, in DMA $(700 \mu \mathrm{l})$ was then carried out at $120{ }^{\circ} \mathrm{C}$ for 20 minutes under an atmosphere of air. Each reaction was quenched with $0.2 \mathrm{M} \mathrm{HCl}(1 \mathrm{ml})$ to ensure the dissolution of all $\left[{ }^{18} \mathrm{~F}\right]$ fluoride from the reaction vessel walls. The radiochemical yield (\%RCY) was evaluated using radioTLC to measure reaction performance, and selected experiments were evaluated with radioHLPC to confirm compound identity.

Table 1: Experiments to test both the ${ }^{18} \mathrm{~F}$ elution efficiency and the QMA eluent mixture's effect on CMRF reaction performance of various ${ }^{18} \mathrm{~F}$ processing methods.

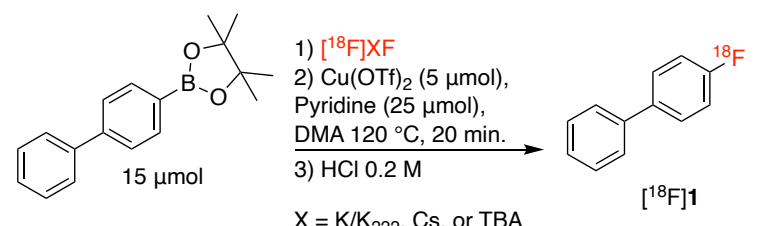

\begin{tabular}{|c|c|c|c|c|c|c|c|c|c|c|}
\hline $\begin{array}{c}\text { Entry } \\
\text { (Reference) }\end{array}$ & Precon. Salt & $\begin{array}{l}\text { Loading } \\
\text { Direction }\end{array}$ & Eluent PTC Salt & Base & Eluting Solvent & $\operatorname{Vol}(\mu \mathrm{l})$ & $\begin{array}{l}\text { MeOH Wash } \\
\quad(1 \mathrm{ml})\end{array}$ & $\begin{array}{l}\quad \%{ }^{18} \mathrm{~F} \\
\text { recovery }\end{array}$ & $\begin{array}{c}\text { Azeotropic drying } \\
(3 \times \mathrm{MeCN})\end{array}$ & \%RCY $\left[{ }^{18} \mathrm{~F}\right] \mathbf{1}^{*}$ \\
\hline 1 & $\mathrm{NaHCO}_{3}(1 \mathrm{M})$ & Forward & $\mathrm{K}_{222}(6.4 \mathrm{mg})$ & $\mathrm{K}_{2} \mathrm{CO}_{3} / \mathrm{K}_{2} \mathrm{C}_{2} \mathrm{O}_{4}$ & $\mathrm{MeCN}: \mathrm{H}_{2} \mathrm{O}(4: 1)$ & 1000 & No & 33 & yes & 3 \\
\hline 2 & $\mathrm{NaHCO}_{3}(1 \mathrm{M})$ & Forward & $\mathrm{K}_{222}(9.5 \mathrm{mg})$ & $\mathrm{K}_{2} \mathrm{CO}_{3}(1.7 \mathrm{mg})$ & $\mathrm{MeCN}: \mathrm{H}_{2} \mathrm{O}(4 \%)$ & 2000 & No & 97 & yes & ND \\
\hline 3 & $\mathrm{NaHCO}_{3}(1 \mathrm{M})$ & Forward & KOTf (10 mg) & $\mathrm{K}_{2} \mathrm{CO}_{3}(50 \mu \mathrm{g})$ & $\mathrm{H}_{2} \mathrm{O}$ & 550 & No & 94 & yes & 8 \\
\hline 4 & KOTf & Forward & KOTf (10 mg) & $\mathrm{K}_{2} \mathrm{CO}_{3}(50 \mu \mathrm{g})$ & $\mathrm{H}_{2} \mathrm{O}$ & 550 & No & 98 & yes & 13 \\
\hline 5 & KOTf & Forward & TВAOTf $(10 \mathrm{mg})$ & ) $\mathrm{Cs}_{2} \mathrm{CO}_{3}(50 \mu \mathrm{g})$ & $\mathrm{H}_{2} \mathrm{O}$ & 550 & No & 99 & yes & 33 \\
\hline 6 & KOTf & Forward & ТВАОTf (5 mg) & - & $\mathrm{H}_{2} \mathrm{O}$ & 550 & No & 96 & yes & 32 \\
\hline 7 & KOTf & Forward & TBAOTf $(10 \mathrm{mg})$ & - & $\mathrm{H}_{2} \mathrm{O}$ & 550 & No & 96 & yes & 24 \\
\hline 8 & KOTf & Reverse & TBAOTf (5 mg) & - & $\mathrm{MeOH}$ & 1000 & Yes & 44 & MeOH Evap & 73 \\
\hline 9 & KOTf & Reverse & TBAOTf $(10 \mathrm{mg})$ & - & $\mathrm{MeOH}$ & 1000 & Yes & 45 & MeOH Evap & 71 \\
\hline 10 & KOTf & Forward & TBAOTf (5 mg) & - & $\mathrm{MeCN}$ & 1000 & Yes & 0 & NR & NR \\
\hline 11 & KOTf & Forward & TBAOTf $(10 \mathrm{mg})$ & - & $\mathrm{MeCN}$ & 1000 & Yes & 0 & NR & NR \\
\hline 12 & KOTf & Forward & TВAOTf (5 mg) & - & EtOH & 1000 & Yes & 81 & EtOH Evap & 55 \\
\hline 13 & KOTf & Forward & TBAOTf $(10 \mathrm{mg})$ & - & EtOH & 1000 & Yes & 79 & EtOH Evap & 62 \\
\hline 14 & KOTf & Forward & TBAOTf (5 mg) & - & $\mathrm{MeOH}$ & 1000 & Yes & $92 \pm 1.4$ & MeOH Evap & $67 \pm 3.1+$ \\
\hline 15 & KOTf & Forward & TBAOTf $(10 \mathrm{mg})$ & - & $\mathrm{MeOH}$ & 1000 & Yes & $93 \pm 2.2$ & MeOH Evap & $64 \pm 1.5^{+}$ \\
\hline 16 & KOTf & Forward & TBAOTf (1 mg) & - & $\mathrm{MeOH}$ & 1000 & Yes & $58 \pm 3.0$ & $\mathrm{MeOH}$ Evap & $40 \pm 1.4^{\dagger}$ \\
\hline 17 & KOTf & Forward & TBAOTf $(10 \mathrm{mg})$ & - & $\mathrm{MeOH}$ & 1000 & No & $95 \pm 0.4$ & MeOH Evap & $72 \pm 8.9+$ \\
\hline
\end{tabular}


Using standard published QMA processing methods (Table 1, entries 1-2) yielded good recoveries of

$113\left[{ }^{18} \mathrm{~F}\right]$ fluoride; however, as expected, the model CMRF reactions did not tolerate the presence of kryptofix 114 and potassium carbonate. Eliminating kryptofix using conditions similar to those published by Makaravage 115 et al. (and those used in our previous work) improved CMRF reaction performance (Table 1, entries 3-4). 116 These experiments also demonstrated the importance of the QMA cartridge preconditioning anion, as 117 reaction performance again increased when the QMA cartridges were conditioned with potassium triflate (0.5 M, $10 \mathrm{ml})$ instead of sodium bicarbonate (1 M, $10 \mathrm{ml})$.

Entries 5-7 showed that TBAOTf in water possessed sufficient eluting power to quantitatively recover $\left[{ }^{18} \mathrm{~F}\right]$ fluoride from the QMA cartridge without the need for an additional carbonate base. We then attempted to elute the ${ }^{18} \mathrm{~F}$ with methanol via a protocol similar to that of the minimalist approach employed by Zischler and coworkers (Table 1, entries 8-9). The ${ }^{18} \mathrm{~F}$ was loaded onto the QMA cartridge in the reverse direction (back-flushing) and then washed with methanol in the forward direction to remove any residual water, after which the ${ }^{18} \mathrm{~F}$ could be recovered by eluting with TBAOTf in methanol $(1 \mathrm{ml}, 5-10$ $\mathrm{mg} / \mathrm{ml}$ ). However, much of the ${ }^{18} \mathrm{~F}$ was lost during the methanol wash step. This was possibly due to a combination of the ${ }^{18} \mathrm{~F}$ being loaded on the front end of the cartridge and the use of a triflate QMA counterion over the standard bicarbonate ion used in previous works.

We then attempted an alternative procedure, this time loading the ${ }^{18} \mathrm{~F}$ onto the QMA cartridge in the forward direction, followed by washing with methanol and eluting the ${ }^{18} \mathrm{~F}$ with the same TBAOTf solution as before (Table 1, entry 15). To our delight, this afforded $\left[{ }^{18} \mathrm{~F}\right]$ TBAF in methanol with acceptable relative ${ }^{18} \mathrm{~F}$ recoveries $(93 \pm 2.2 \%)$. The methanol could then be removed via evaporation at $85{ }^{\circ} \mathrm{C}$ under a stream of argon to afford dry and carbonate-free $\left[{ }^{18} \mathrm{~F}\right] \mathrm{TBAF}$. The model CMRF reaction showed excellent reaction performance with both single batch and aliquoted $\left[{ }^{18} \mathrm{~F}\right] \mathrm{TBAF}$ prepared in this manner. Additionally, the reaction showed tolerance to TBAOTf loads between 5-10 mg (Table 1, entries 14-15). Lower TBAOTf loads $(1 \mathrm{mg})$ in the QMA eluent solution often failed to completely elute the ${ }^{18} \mathrm{~F}$ from the QMA cartridge and negatively influenced reaction performance (Table 1, entry 16). Finally, we evaluated the importance of the methanol wash step to remove residual water from the QMA cartridge (Table 1, entry 17). Skipping this step resulting in marginally higher $\%{ }^{18} \mathrm{~F}$ recoveries and, unexpectedly, had no significantly deleterious effects on reaction performance. Furthermore, the elimination of the (toxic) methanol wash increased the method's operational simplicity so that it can be used directly on most ${ }^{18} \mathrm{~F}$ automated synthesizers, a further advantage when considering prospective large-scale routine radiotracer productions.

We also evaluated both acetonitrile and ethanol as alternative elution solvents, with ethanol being more suited to clinical radiotracer production due to its lower toxicity compared to acetonitrile or methanol 
protic solvents are required for this method to work. TBAOTf in ethanol successfully eluted the ${ }^{18} \mathrm{~F}$, albeit with slightly weaker elution efficiency and lower reaction performance.

147 To evaluate our ${ }^{18} \mathrm{~F}$ processing method's performance and scalability, we applied it to a DoE optimization and subsequent radiosynthesis automation of $\left[{ }^{18} \mathrm{~F}\right]$ olaparib. $\left[{ }^{18} \mathrm{~F}\right]$ Olaparib is a tracer of potential clinical importance as a "second-generation" variant of $\left[{ }^{18} \mathrm{~F}\right] \mathrm{PARPi}$, a radiotracer that is currently in clinical trials for the imaging of the DNA repair enzyme PARP-1..$^{20,21}$ The recently reported copper-mediated radiosynthesis of $\left[{ }^{18} \mathrm{~F}\right]$ olaparib reacts azeotropically dried $\left[{ }^{18} \mathrm{~F}\right] \mathrm{KF}$ (eluted from a QMA cartridge using kryptofix, potassium carbonate, and potassium oxalate (Table 1, entry 1)) with a trimethylsilylethoxymethyl (SEM) protected pinacol boronate precursor OLA-BPin, in the presence of $\left[\mathrm{Cu}(\mathrm{OTf})_{2}(\mathrm{Impy})_{4}\right]$ as the copper mediator (Figure 2). ${ }^{22}$ The reaction is carried out under air in 1,3-dimethyl-2-imidazolidinone (DMI) at $120^{\circ} \mathrm{C}$ for 20 minutes, after which the SEM protecting group is removed by stirring the reaction mixture with TFA at $120^{\circ} \mathrm{C}$ for a further 15 minutes to afford [ ${ }^{18} \mathrm{~F}$ ]olaparib after HPLC purification (activity yield: $6 \pm 5 \%$, automated process). ${ }^{20,22}$
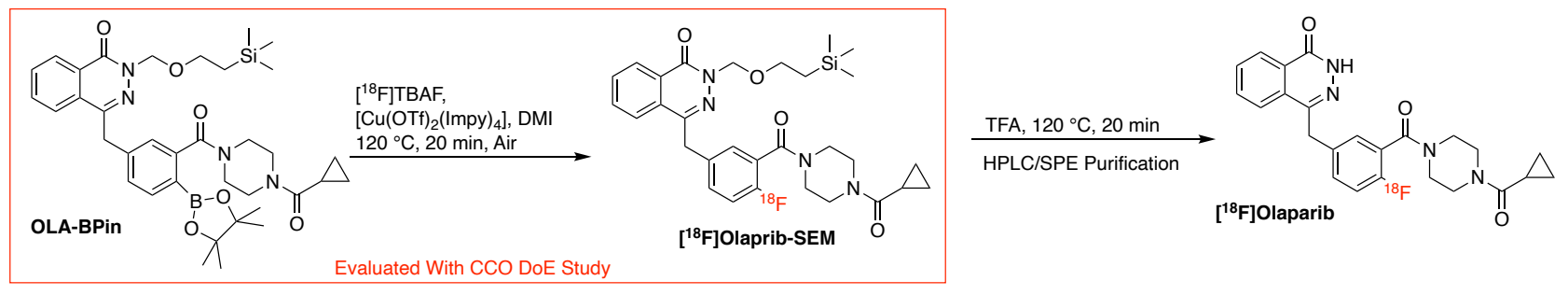

Figure 2: Radiosynthesis of $\left[{ }^{18} \mathrm{~F}\right]$ olaparib via the CMRF of the precursor OLA-BPin.

Having synthesized the arylboronate precursor via the published route (see supplementary information 1.2), we used the DoE software MODDE Go (Sartorious, Germany) to design a response surface optimization study of the CMRF step using an orthogonal central composite design (CCO) (see supplementary information 3.2.4). The resulting study consisted of 17 experiments (14 experimental points, 3 centerpoints) to evaluate the effects of the precursor load (Pre, $5-25 \mu \mathrm{mol}$ ), copper mediator load (CuC, $5-25 \mu \mathrm{mol}$ ), and solvent volume (SoV, $300-600 \mu \mathrm{l}$ ) on the reaction's performance (S.Table 1). The DoE study was conducted using three ${ }^{18} \mathrm{~F}$ cyclotron target washes (over three days), each trapped and eluted from a single QMA cartridge. The resulting methanolic $\left[{ }^{18} \mathrm{~F}\right] \mathrm{TBAF}$ solution was then aliquoted (150 $\left.\mu \mathrm{l}\right)$ into single-use glass reaction tubes ( 6 runs per target wash), and the methanol was evaporated from each reaction vessel at $90{ }^{\circ} \mathrm{C}$ under a stream of argon. Finally, the reaction mixture required by the DoE study was added to the dry $\left[{ }^{18} \mathrm{~F}\right] \mathrm{TBAF}$, and the reaction was allowed to stir for $120{ }^{\circ} \mathrm{C}$ for 20 minutes. After quenching with $0.1 \mathrm{M} \mathrm{HCl}$, the reaction performance (\%RCY) of the CMRF step was measured by radioTLC, and selected runs were analyzed via radioHPLC to verify product identity against a non-radioactive standard. 
After acquiring the \%RCY data, the resulting data set was found to be skewed and was thus transformed ($\log _{10} Y$ ) to ensure a normal distribution. Multiple linear regression (MLR) was used to construct a response surface model from the transformed data set; the summary of fit statistics suggested the resulting model to valid and predictive $\left(R^{2}=0.972\right.$ (goodness of model fit); $Q^{2}=0.900$ (goodness of model prediction); S. Figure 5). The results of the DoE study showed all main factors (precursor load, copper mediator load, and solvent volume) to have significant effects \%RCY (S.Figure 6). The copper mediator load and solvent volume terms were found to possess significant quadratic behaviors (they contribute to curvature in the response surface). Moreover, factor interactions (where one setting affects the behavior of another) between the precursor and copper mediator loads and between the copper mediator load and the solvent volume (copper mediator concentration) were detected. Plotting the response surface over the investigated ranges revealed that the CMRF synthesis of $\left[{ }^{18} \mathrm{~F}\right]$ olaparib performed better at lower reaction concentrations (higher solvent volume) and that the optimal amounts of the precursor and copper mediator were approximately $10 \mu \mathrm{mol}$ and $22 \mu \mathrm{mol}$, respectively (Figure 3 ).

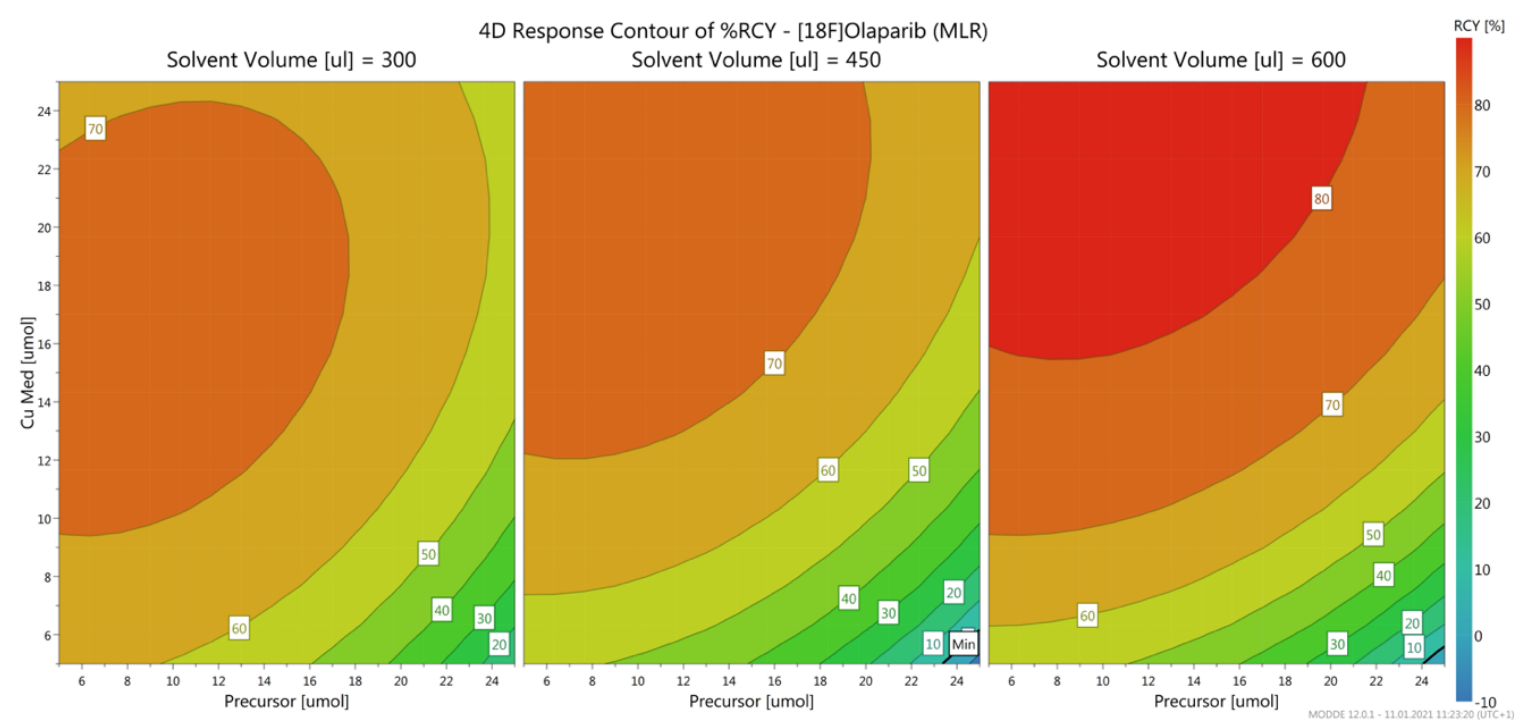

Figure 3: 4D-plot of the response surface model generated from the DoE optimization study of the CMRF synthesis of $\left[{ }^{18} \mathrm{~F}\right]$ olaparib.

To verify the DoE study results and the scalability of the ${ }^{18} \mathrm{~F}$ processing method, the radiolabeling of $\left[{ }^{18} \mathrm{~F}\right]$ olaparib was performed manually in triplicate using two sets of optimal conditions from the response surface model. To simulate an automated tracer production, a full batch preparation of $\left[{ }^{18} \mathrm{~F}\right]$ TBAF was used for each replicate experiment instead of aliquots of $\left[{ }^{18} \mathrm{~F}\right] \mathrm{BBAF}$ from a single QMA cartridge elution. Performing the synthesis with $10.5 \mu \mathrm{mol}$ OLA-BPin $(7 \mathrm{mg}), 22 \mu \mathrm{mol}$ [Cu(OTf $\left.)_{2}(\mathrm{Impy})_{4}\right](18 \mathrm{mg})$, and $700 \mu \mathrm{l}$ DMI (total solvent volume) afforded the SEM protected radiolabeled intermediate $\left[{ }^{18} \mathrm{~F}\right]$ olaparib-SEM in good radiochemical yields in line with those predicted by the response surface model ( $78 \pm 6 \% R C Y, n=4)$. The validity of the model was again tested by performing the same synthesis using $15.6 \mu \mathrm{mol}$ OLA-BPin $(10.5 \mathrm{mg})$ and $26 \mu \mathrm{mol}\left[\mathrm{Cu}(\mathrm{OTf})_{2}(\mathrm{Impy})_{4}\right](22 \mathrm{mg})$, in $100 \mu \mathrm{l}$ DMI. These conditions again afforded 
$\left[{ }^{18} \mathrm{~F}\right]$ olaparib-SEM in good radiochemical yields ( $85 \pm 3 \% \mathrm{RCY}, \mathrm{n}=3$ ). These conditions proved slightly better but used more of the expensive copper-mediator and precursor; therefore, the previous conditions were favored for further development. Deprotection with TFA $(700 \mu \mathrm{l})$ at $120^{\circ} \mathrm{C}$ for 15 minutes was found to remove the SEM protecting group with $>95 \%$ efficiency to afford $\left[{ }^{18} \mathrm{~F}\right]$ olaparib.

202

The optimized $\left[{ }^{18} \mathrm{~F}\right.$ ]olaparib radiosynthesis was translated onto both GE FX N Pro (GE, Uppsala, Sweden) and an Elixys FLEX/CHEM radiosynthesizers to measure the total radiosynthesis performance (activity yield, \%AY) and to prepare the tracer for preclinical imaging experiments (see supplementary Information 3.3). The synthesis was performed via a modified version of the process described in the literature. ${ }^{22}$ When performed using an Elixys FLEX/CHEM coupled to a PURE/FORM synthesis module (Sofie Bioscience, USA), the optimized synthesis was able to afford $\left[{ }^{18} \mathrm{~F}\right]$ olaparib with a non-decay corrected activity yield (\%AY) up to $41 \%$ ( $80 \% \mathrm{RCY}$ (decay corrected), $25-58 \mathrm{GBq} / \mu \mathrm{mol}$, (S.Table 3 ), a significant improvement over the synthesis described by Guibbal et al. ${ }^{22}$ When performed using an FX N Pro, synthesis performance was similar to the performance previously described (5.4 $\pm 1.6 \% \mathrm{AY} ; 9.3 \pm 3.3 \% \mathrm{RCY}$, S.Table 5). On the FX N Pro, syntheses also showed marked differences in product molar activity, returning values up to 331.4 $\mathrm{GBq} / \mu \mathrm{mol}$. The higher molar activities correlated with longer bombardment times, even though activity yields remained fairly constant under these parameters. The marked differences in synthesis performance (with respect to activity yields) between the two synthesis modules could be due to several factors related to each module's construction. The Elixys is a cassette-based system that features a standard $5 \mathrm{ml}$ Wheaton V-vial as the reactor vessel, while the more widely used FX N Pro is a fixed fluid path system featuring a 17 $\mathrm{ml}$ reactor. As the volume of the reactor vessel is known to affect the performance of CMRF reactions, this could be one reason for lower synthesis performance on the FX N Pro. Additionally, the volume available to dilute the reaction mixture prior to the first HLB trapping (before HPLC) is also much lower on the FX N Pro (max $15 \mathrm{ml}$ ), and this may result in a weaker trapping of the product $\left[{ }^{18} \mathrm{~F}\right]$ olaparib on the HLB cartridge, further reducing synthesis performance. More work is needed to improve the overall process performance on the FX N Pro; however, the synthesis behaves as predicted by the DoE study when performed using the Elixys FLEX/CHEM (with respect to \%RCY).

In conclusion, we have implemented an ${ }^{18} \mathrm{~F}$ processing method that is compatible with CMRF reaction conditions on both small (experiments using aliquots of QMA eluted $\left[{ }^{18} \mathrm{~F}\right] \mathrm{TBAF}$ ) and large scale (single batch) radiosyntheses. Moreover, through the synthesis of $\left[{ }^{18} \mathrm{~F}\right]$ olaparib, we could demonstrate that $\left[{ }^{18} \mathrm{~F}\right]$ TBAF produced in this way can be conveniently used for small scale CMRF optimization studies using DoE, and importantly, that these results can then be scaled up to full batch tracer productions using automated radiosynthesizers. We have shown that this ${ }^{18} \mathrm{~F}$ processing method will help unlock the potential of the DoE approach to aid in the establishment of efficient radiotracer production processes using the CMRF methodology. This will further expedite both the preclinical tracer development process and the translation of the CMRF methodology to routine clinical tracer productions. 
M. Tredwell, S. M. Preshlock, N. J. Taylor, S. Gruber, M. Huiban, J. Passchier, J. Mercier, C. Génicot and V. Gouverneur, Angew. Chemie Int. Ed., 2014, 53, 7751-7755.

2 A. V Mossine, A. F. Brooks, K. J. Makaravage, J. M. Miller, N. Ichiishi, M. S. Sanford and P. J. H. Scott, Org. Lett., 2015, 17, 5780-5783.

3 K. J. Makaravage, A. F. Brooks, A. V. Mossine, M. S. Sanford and P. J. H. H. Scott, Org. Lett., 2016, 18, 5440-5443.

4 J. S. Wright, T. Kaur, S. Preshlock, S. S. Tanzey, W. P. Winton, L. S. Sharninghausen, N. Wiesner, A. F. Brooks, M. S. Sanford and P. J. H. Scott, Clin. Transl. Imaging, 2020, 8, 167-206.

5 L. Allott and E. O. Aboagye, Mol. Pharm., 2020, 17, 2245-2259.

6 P. M. Murray, F. Bellany, L. Benhamou, D.-K. Bučar, A. B. Tabor and T. D. Sheppard, Org. Biomol. Chem., 2016, 14, 2373-2384.

7 G. D. Bowden, B. J. Pichler and A. Maurer, Sci. Rep., 2019, 9, 11370.

8 B. D. Zlatopolskiy, J. Zischler, P. Krapf, F. Zarrad, E. A. Urusova, E. Kordys, H. Endepols and B. Neumaier, Chem. - A Eur. J., 2015, 21, 5972-5979.

9 S. Preshlock, S. Calderwood, S. Verhoog, M. Tredwell, M. Huiban, A. Hienzsch, S. Gruber, T. C. Wilson, N. J. Taylor, T. Cailly, M. Schedler, T. L. Collier, J. Passchier, R. Smits, J. Mollitor, A. Hoepping, M. Mueller, C. Genicot, J. Mercier and V. Gouverneur, Chem. Commun., 2016, 52, 8361-8364.

10 A. V Mossine, A. F. Brooks, N. Ichiishi, K. J. Makaravage, M. S. Sanford and P. J. H. Scott, Sci. Rep., 2017, 7, 233.

11 X. Zhang, F. Basuli and R. E. Swenson, J. Label. Compd. Radiopharm., 2019, 62, 139-145.

12 D. Antuganov, M. Zykov, V. Timofeev, K. Timofeeva, Y. Antuganova, V. Orlovskaya, O. Fedorova and R. Krasikova, European J. Org. Chem., 2019, 2019, 918-922.

13 R. Richarz, P. Krapf, F. Zarrad, E. A. Urusova, B. Neumaier and B. D. Zlatopolskiy, Org. Biomol. Chem., 2014, 12, 8094-8099.

14 F. Zarrad, B. Zlatopolskiy, P. Krapf, J. Zischler and B. Neumaier, Molecules, 2017, $22,2231$.

15 S. O. Lahdenpohja, N. A. Rajala, J. Rajander and A. K. Kirjavainen, EJNMMI Radiopharm. Chem., 2019, 4, 28.

16 J. Zischler, N. Kolks, D. Modemann, B. Neumaier and B. D. Zlatopolskiy, Chem. - A Eur. J., 2017, 23, 3251-3256.

17 J. A. H. Inkster, V. Akurathi, A. W. Sromek, Y. Chen, J. L. Neumeyer and A. B. Packard, Sci. Rep., 2020, 10, 6818.

18 V. Orlovskaya, D. Antuganov, O. Fedorova, V. Timofeev and R. Krasikova, Appl. Radiat. Isot., 2020, 163, 109195.

19 R. N. Krasikova, Molecules, 2020, 25, 4365.

20 T. C. Wilson, M.-A. Xavier, J. Knight, S. Verhoog, J. B. Torres, M. Mosley, S. L. Hopkins, S. Wallington, P. D. Allen, V. Kersemans, R. Hueting, S. Smart, V. Gouverneur and B. Cornelissen, J. Nucl. Med., $2019,60,504-510$. 
B. Carney, G. Carlucci, B. Salinas, V. Di Gialleonardo, S. Kossatz, A. Vansteene, V. A. Longo, A. 392.

22 F. Guibbal, P. G. Isenegger, T. C. Wilson, A. Pacelli, D. Mahaut, J. B. I. Sap, N. J. Taylor, S. Verhoog, S. Preshlock, R. Hueting, B. Cornelissen and V. Gouverneur, Nat. Protoc., 2020, 15, 1525-1541.

\section{Author Contributions}

Gregory Bowden (G.B.) and Nantanat Chailangger designed and performed the radiochemical experiments. G.B. performed the organic synthesis and chemically characterized the compounds. G.B. designed the DoE study and analyzed the data. G.B. established the automated radiosyntheses on both the Elixys FLEX/CHEM and GE FX N Pro. The manuscript was written and reviewed by G.B., Andreas Maurer, and Bernd Pichler.

\section{Acknowledgments}

We would like to thank the Adolf Leuze Foundation and the Werner Siemens Stiftung for their financial 284 contributions toward this work. Funding for this work was also provided by the Deutsche Forschungsgemeinschaft (DFG, German Research Foundation) under Germany's Excellence Strategy EXC 2180 - 390900677. We would also like to thank Dr. Gerald Reischl, Marko Matijevic, and other colleagues in the radiopharmacy at the Werner Siemens Imaging Center for the delivery of $\left[{ }^{18} \mathrm{~F}\right]$ fluoride and for technical support. 